\title{
Screening for diabetes in Kuwait and evaluation of risk scores
}

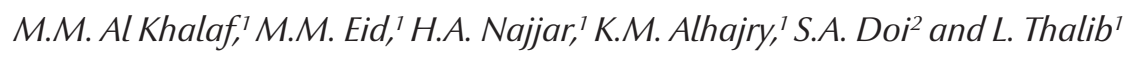

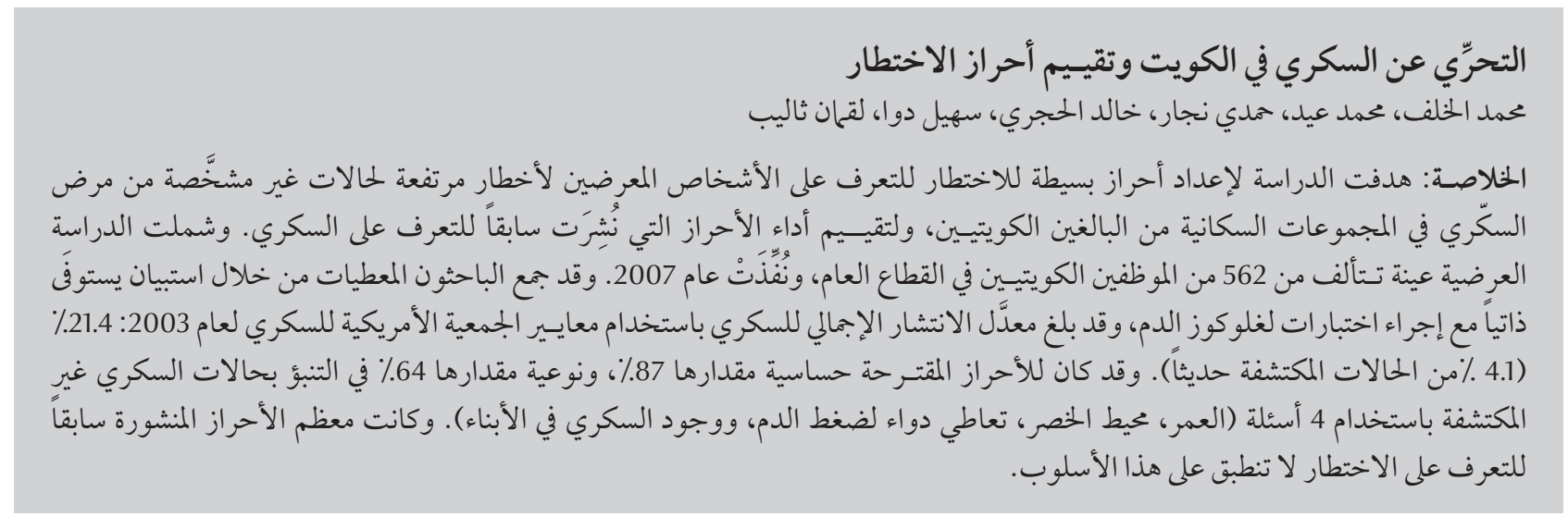

ABSTRACT This study aimed to develop a simple risk score to identify individuals at high risk for undiagnosed diabetes in the Kuwaiti adult population and to assess the performance of previously published diabetes risk scores. A cross-sectional survey with a sample of 562 Kuwaiti public sector employees was carried out in 2007. Data were collected through a self-administered questionnaire and a blood glucose test. The overall prevalence of diabetes using American Diabetes Association 2003 criteria was 21.4\% (4.1\% newly detected). The proposed score had $87 \%$ sensitivity and $64 \%$ specificity in predicting undetected diabetes using only 4 questions (age, waist circumference, use of blood pressure medication and diabetes in a sibling). Most previously published risk scores were not applicable to this population.

\section{Dépistage du diabète au Koweït et évaluation des scores de risque}

RÉSUMÉ Cette étude visait à mettre au point un score de risque simple destiné à identifier les individus à haut risque de diabète non diagnostiqué dans la population adulte koweïtienne et à évaluer la performance des scores de risque du diabète publiés auparavant. Une étude transversale sur un échantillon de 562 employés du secteur public koweïtien a été réalisée en 2007. Les données ont été recueillies au travers d'un auto-questionnaire et d'un test de glycémie. La prévalence globale du diabète selon les critères établis en 2003 par l'Association américaine du diabète était de $21,4 \%$ (4,1 \% de diabète nouvellement détecté). Le score proposé présentait $87 \%$ de sensibilité et $64 \%$ de spécificité dans la prédiction de diabète non détecté en se basant uniquement sur 4 questions (âge, tour de taille, prise de médicaments pour la pression artérielle et cas de diabète dans la fratrie). La plupart des scores de risque publiés antérieurement n'étaient pas applicables à cette population. 


\section{Introduction}

The rapid increase in the incidence of diabetes mellitus has led to heightened public concern over prevention and treatment [1]. Studies suggest that onethird of all people with diabetes may be undiagnosed [2]; therefore early detection of undiagnosed diabetes and the identification of those at high risk are crucial steps in reducing the associated health care burden $[3,4]$. It is known that the delay from disease onset to diagnosis may sometimes exceed 10 years [5] and that one or more vascular complications are already present by the time of diagnosis $[6,7]$.

Identifying those at high risk allows appropriate interventions to be initiated so that the transition to overt diabetes, with its attendant complications, can be prevented or delayed [8]. Questionnaires based on multivariate risk factor models have been used in a number of populations, with encouraging results. The aim of all these is to limit the proportion of the population that needs to undergo laboratory-based diagnostic glucosemeasurements. However, before their widespread use it is necessary to validate the risk scores in different populations because a single questionnaire might not be universally applicable.

Arab countries are undergoing a rapid epidemiological transition and are reporting high rates of type 2 diabetes in the population [9-11]. Nonetheless, there is an intense debate about how this should be managed and, while much research has focussed on diagnosed diabetics, little is known about the prevalence and risk factors associated with those living with diabetes but undiagnosed. None of these countries has any systematic screening programme for diabetes. In this context, we aimed to explore the prevalence of undiagnosed diabetes and the factors associated with it, so that a pen and paper risk score that is non-invasive and simple to use could be developed for the Kuwaiti population. We also aimed to assess locally the performance of previously published diabetes risk scores.

\section{Methods}

Our findings were based on a crosssectional survey carried out during March to April 2007.

\section{Sample size determination}

The prevalence of type 2 diabetes mellitus in the Kuwaiti adult population is known to be about $15 \%$ [12]. Based on findings that suggested that about onethird of diabetics are undetected [4], we estimated the prevalence of unknown diabetes to be $5 \%$. With a type 1 error of $5 \%$, a power of $80 \%$ and an allowed error of $3 \%$ in either direction, we required a sample size of at least 413 to estimate the prevalence of unknown diabetes in this population.

\section{Study population}

We used sex-stratified multi-stage cluster sampling among public sector employees in Kuwait. Of 9 government ministries 5 were randomly selected. Sampling from each ministry was proportional to the size of each of these ministries. Each ministry building was divided into 7 clusters with one and half floors per cluster. The number of clusters required was calculated based on the sample size requirement and clusters to be included were randomly selected. All adult males and females in the selected clusters were approached. Stratificationbased onsexwas possibleas males and females had separate working areas. Pregnant women, who are prone to develop gestational diabetes, were excluded.

Of a total of 5430 employees in Kuwait, we approached 578 and of these 562 agreed to participate (a response rate of $98 \%$ ). The reasons for refusal were not determined but unwillingness to provide a finger-prick sample may have been a reason for some of the refusals.
The Ethics Committee of the Faculty of Medicine, University of Kuwait, approved this study. We also obtained written consent from each participant.

\section{Data collection}

Data were collected through a selfadministered questionnaire and a blood glucose test.

\section{Detection of diabetes}

A total of 97 participants reported that they had been already diagnosed with diabetes by a physician. The diabetes status of 2 participants was unknown. This left 463 to be classified based on our blood glucose measurements. We asked the participants who agree to participate and who consented to fast for more than 8 hours for testing the following day. Blood glucose was measured using the Accu-Check Go blood glucose meter (Roche Diagnostics, Mannheim, Germany). Diagnosis of diabetes was based on the American Diabetes Association (ADA) 2003 criteria [13]. If fasting blood glucose was $\geq 7.0 \mathrm{mmol} / \mathrm{L}$ or random glucose $\geq 11.1 \mathrm{mmol} / \mathrm{L}$ participants were classified as newly diagnosed diabetes. Those with fasting glucose levels between 5.6-6.9 mmol/L were classified as having impaired fasting glucose or pre-diabetic status.

\section{Screening tools}

Our research instrument consisted of blood glucose measurements, anthropometric measures (weight, height, waist circumference) and a speciallydesigned self-administered questionnaire. The questionnaire consisted of 24 items about physical activity, family history of diabetes and food and drink consumption and dieting. To develop the questionnaire we performed a Medline search in March 2007 using keywords that include diabetes. We identified 8 tools that were non-invasive and had clear criteria for screening that could be applied to our study. The risk screening tools were from the following populations/sources: Thailand [14], Oman [15], Rotterdam (The Netherlands) 
[16], Denmark [17], Cambridge (England) [18], the ADA (United States) [19], Finland [20] and India [21]. We pooled the published risk factors and included them in the questionnaire to which the required demographic variables were added.

\section{Statistical methods}

For the published risk scores, sensitivity and specificity were computed using the cut-offs proposed by the original publications. Then, for comparison, specificity was calculated using an adjusted cut-off that resulted in $75 \%$ to $85 \%$ sensitivity within our study population. The survey data were entered into a forward stepwise logistic regression model to identify the most important and independent predictors for undetected diabetes. Points were assigned to each variable based on the magnitude of the regression coefficients. Each beta coefficient was rounded to the nearest integer. The risk score for an individual patient was determined by assigning points for each factor present and summing these. A receiver-operating characteristics (ROC) curve and the area under the curve were used to evaluate the risk score developed and to determine a cut-off for our population based on optimal sensitivity.

\section{Results}

A total of 562 participants were initially recruited to the study, with a mean age of 36.2 (standard deviation 8.9) years. The crude prevalence of total diabetes in the Kuwaiti adult population was $21.4 \%$ (120/560). There were 97 participants [17.3\%; 95\% confidence interval (CI): $14.4 \%-20.7 \%]$ who reported a previous diagnosis of diabetes and 23 (4.1\%; $95 \%$ CI: $2.7 \%-6.1 \%)$ with undetected diabetes.

Table 1 describes the study population after excluding those already diagnosed with diabetes by a physician.

\begin{tabular}{|c|c|c|c|c|c|c|}
\hline \multirow[t]{2}{*}{ Variable } & \multicolumn{2}{|c|}{$\begin{array}{l}\text { Impaired fasting blood } \\
\text { glucose }(n=57)^{\mathrm{a}}\end{array}$} & \multicolumn{2}{|c|}{$\begin{array}{l}\text { Newly detected diabetic } \\
\qquad(n=23)^{\mathrm{a}}\end{array}$} & \multicolumn{2}{|c|}{$\begin{array}{l}\text { Normoglycaemic } \\
\qquad(n=380)^{\mathrm{a}}\end{array}$} \\
\hline & Mean & SD & Mean & SD & Mean & SD \\
\hline Age (years) & 37.3 & 8.0 & 42.9 & 7.7 & 34.7 & 8.5 \\
\hline Height $(\mathrm{cm})$ & 165.0 & 11.0 & 166.4 & 8.1 & 165.4 & 9.7 \\
\hline Weight (kg) & 85.0 & 26.0 & 90.0 & 12.7 & 77.2 & 18.1 \\
\hline $\operatorname{BMI}\left(\mathrm{kg} / \mathrm{m}^{2}\right)$ & 30.8 & 6.5 & 32.5 & 4.5 & 28.1 & 5.6 \\
\hline \multirow[t]{2}{*}{ Waist circumference $(\mathrm{cm})$} & 98.3 & 16.0 & 108.1 & 12.2 & 94.8 & 15.3 \\
\hline & No. & $\%$ & No. & $\%$ & No. & $\%$ \\
\hline \multicolumn{7}{|l|}{ Age group (years) } \\
\hline $20-29$ & 12 & 8.1 & 2 & 1.3 & 135 & 90.6 \\
\hline $30-39$ & 23 & 13.3 & 4 & 2.3 & 146 & 84.4 \\
\hline$\geq 40$ & 22 & 15.9 & 17 & 12.3 & 99 & 71.7 \\
\hline \multicolumn{7}{|l|}{$\operatorname{Sex}$} \\
\hline Male & 19 & 8.8 & 11 & 5.1 & 187 & 86.2 \\
\hline Female & 38 & 15.6 & 12 & 4.9 & 193 & 79.5 \\
\hline \multicolumn{7}{|l|}{$B M I\left(\mathrm{~kg} / \mathrm{m}^{2}\right)$} \\
\hline Underweight $(<19)$ & 0 & 0.0 & 0 & 0.0 & 6 & 100.0 \\
\hline Normal (19-25) & 9 & 7.7 & 2 & 1.7 & 106 & 90.6 \\
\hline Overweight (> 25-30) & 23 & 12.2 & 6 & 3.2 & 160 & 84.7 \\
\hline Obese (> 30-40) & 21 & 16.6 & 13 & 10.2 & 93 & 73.2 \\
\hline Morbidly obese (> 40) & 4 & 19.0 & 2 & 9.5 & 15 & 71.4 \\
\hline \multicolumn{7}{|l|}{ Waist circumference $(\mathrm{cm})$} \\
\hline \multicolumn{7}{|l|}{ Males: } \\
\hline$<102$ & 5 & 4.3 & 2 & 1.7 & 110 & 94.0 \\
\hline$\geq 102$ & 13 & 13.1 & 9 & 9.1 & 77 & 77.8 \\
\hline \multicolumn{7}{|l|}{ Females: } \\
\hline$<88$ & 18 & 17.0 & 1 & 0.9 & 87 & 82.1 \\
\hline$\geq 88$ & 21 & 15.2 & 11 & 8.0 & 106 & 76.8 \\
\hline
\end{tabular}

${ }^{a}$ American Diabetes Association 2003 criteria [13].

$B M I=$ body mass index . 
Those whose diabetes status was unknown were divided into 3 groups based on the glucose test: newly detected diabetics $(n=23)$, those who had impaired levels of glucose $(n=57)$ and those without any rise in the glucose levels $(n=380)$ (normoglycaemic). We compared these 3 groups for their anthropometric measures and other risk factors.

The risk factors for undetected diabetes were evaluated using forward stepwise modelling (Tables 2 and 3). After multiple logistic regression, age was first significant independent predictor to be included in the model significant independent predictor [odds ratio (OR) 3.72, 95\% CI: 1.05-13.2], followed by waist circumference (OR 6.89, 95\% CI: 1.95-24.3), use of blood pressure medication (OR 2.66, 95\% CI: $1.00-7.05)$ and family history of a sibling with diabetes (OR 2.66,95\% CI: 1.08-6.54) (Table 3). A score for each variable in the model was calculated by multiplying the $\beta$-coefficient by 10 (Table 3). The ROC curve of the score we developed had an area under the curve of 0.82 (Figure 1). We found that the optimal cut-off ( $\geq 32$ points) had an acceptable sensitivity of $87 \%$ and specificity of $64 \%$ for predicting undetected diabetes.

A list of the risk factors investigated in this study and those used in the other published risk scores is given for comparison in Table 4 [14-21]. These risk scores were tested on participants in our study. All of the risk scores performed worse than our score in terms of sensitivity and specificity at detecting undiagnosed diabetes in our population (Table 5). The worst performing scores in terms of specificity (after adjustment) were the Rotterdam, Thai and ADA scores. However, if the cut-offs were adjusted appropriately, the performance of the other scores improved slightly. The standardized cut-offs were generally higher than those in the populations for whom the risk scores were originally developed, except for the Rotterdam and Danish scores, which needed to be adjusted downwards.

\section{Discussion}

In this study the crude prevalence of total diabetes in Kuwait was high (21.4\%), particularly given the young age of the population that we surveyed (mean age 36.2 years). It is possible that a high prevalence of diabetes is common to the region, given the estimated $16 \%$ to

\begin{tabular}{|c|c|c|}
\hline Variable & OR $(95 \% \mathrm{CI})$ & $P$-value \\
\hline \multicolumn{3}{|l|}{ Sex } \\
\hline Female & Ref. & \\
\hline Male & $1.04(0.45-2.40)$ & 0.93 \\
\hline Female with macrosomia & $2.11(0.59-7.52)$ & 0.25 \\
\hline \multicolumn{3}{|l|}{ Age (years) } \\
\hline $20-34$ & Ref. & \\
\hline$\geq 35$ & $6.82(2.00-23.3)$ & 0.002 \\
\hline \multicolumn{3}{|l|}{$B M I$} \\
\hline $\begin{array}{l}\mathrm{BMI} \text { per } \mathrm{kg} / \mathrm{m}^{2} \text { increment from } 15 \\
\mathrm{~kg} / \mathrm{m}^{2}\end{array}$ & $1.10(1.04-1.16)$ & 0.002 \\
\hline \multicolumn{3}{|l|}{ Waist circumference $(\mathrm{cm})$} \\
\hline$<100$ & Ref. & \\
\hline$\geq 100$ & $10.8(3.17-37.1)$ & $<0.001$ \\
\hline \multicolumn{3}{|l|}{ Exercise } \\
\hline$<65$ years and little or no exercise & $1.90(0.43-8.28)$ & 0.40 \\
\hline Leisure time physical activity & $1.16(0.49-2.74)$ & 0.74 \\
\hline Physical activity $<4$ hours per week & $1.18(0.34-4.09)$ & 0.79 \\
\hline \multicolumn{3}{|l|}{ Diet } \\
\hline $\begin{array}{l}\text { Consumption of vegetables, fruits or } \\
\text { berries }\end{array}$ & $1.05(0.45-2.43)$ & 0.91 \\
\hline \multicolumn{3}{|l|}{ Smoking status } \\
\hline Non-smoker & Ref. & \\
\hline Previous smoker & $3.09(0.96-9.91)$ & 0.05 \\
\hline Current smoker & $0.66(0.19-2.32)$ & 0.52 \\
\hline \multicolumn{3}{|l|}{ Medical history } \\
\hline Parent with diabetes & $1.60(0.65-3.97)$ & 0.31 \\
\hline Sibling with diabetes & $3.46(1.48-8.07)$ & 0.004 \\
\hline $\begin{array}{l}\text { Both siblings and parent with } \\
\text { diabetes }\end{array}$ & $2.87(1.20-6.86)$ & 0.02 \\
\hline On steroids & $2.50(0.81-7.78)$ & 0.11 \\
\hline Has hypertension & $2.43(0.86-6.85)$ & 0.09 \\
\hline Previous diagnosis of hypertension & $4.66(1.87-11.6)$ & $<0.001$ \\
\hline Currently on hypertension treatment & $3.92(1.36-11.3)$ & 0.01 \\
\hline
\end{tabular}

Ref. $=$ reference category; $B M I=$ body mass index; $O R=$ odds ratio; $C l=$ confidence interval.
$24 \%$ prevalence of diabetes reported from neighbouring countries $[10,22]$. In contrast to these figures, the crude prevalence of total diabetes was $9.3 \%$ in the United States of America population in 1999-2002 [23].

Previously published risk scores have several variables in common which are (in order of importance): age, hypertension, obesity/waist circumference/ body mass index, family history, sex, physical activity and smoking [14-21]. Although these risk factors are common 


\begin{tabular}{|c|c|c|c|}
\hline \multirow[t]{2}{*}{ Variable } & \multicolumn{3}{|c|}{ Multiple logistic regression } \\
\hline & $\beta$-coefficient & OR $(95 \% \mathrm{CI})$ & Risk score \\
\hline Intercept & -5.018 & - & - \\
\hline Sibling with diabetes & 0.979 & $2.66(1.08-6.54)$ & 10 \\
\hline Has hypertension previously & 0.978 & $2.66(1.00-7.05)$ & 10 \\
\hline Age $\geq 35$ years & 1.315 & $3.72(1.05-13.2)$ & 13 \\
\hline Waist circumference $\geq 100 \mathrm{~cm}$ & 1.930 & $6.89(1.95-24.3)$ & 19 \\
\hline
\end{tabular}

A score for each variable in the model was calculated by multiplying the $\beta$-coefficient by 10 . A score of $\geq 32$ points indicated a high risk for having diabetes. $\mathrm{OR}=$ odds ratio; $\mathrm{Cl}=$ confidence interval.

across populations, their relative importance varies from population to population. Obviously, some risk factors are not applicable to all populations; e.g. use of a bicycle (in a questionnaire from the Netherlands) may not be a risk factor in a society that does not use bicycles as a common mode of transport [16]. The inclusion of specific medications and smoking may also be problematic because the rate of prescription drug use and smoking show large variations in different regions and over time. Because their relative importance varies from population to population, key risk factors for each population need to be established. In our population of Kuwaiti public sector employees we were able to define 4 risk factors that were associated with diabetes risk after multiple regression analysis: age $\geq 35$ years, waist circumference $\geq 100 \mathrm{~cm}$, use of blood pressure medication and family history of diabetes in a sibling. It is interesting to note that sex-specific waist circumference was not an independently associated risk factor for undetected diabetes in our population and only waist circumference $\geq 100 \mathrm{~cm}$ was maintained in multivariate analysis. This may be explained by excess weight being equally prevalent in females and males.

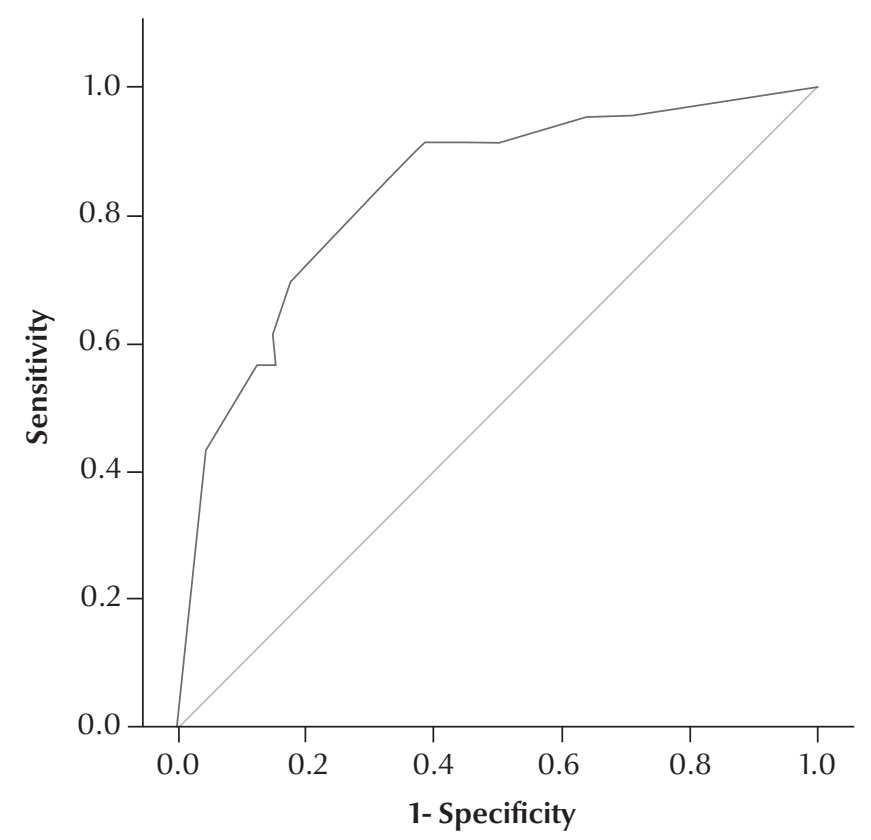

Figure 1 Receiver operating characteristics (ROC) curve showing performance of the score in this study (area under curve $=\mathbf{0 . 8 2}$ )
When we assessed other published risk scores incorporating these risk factors, the cut-offs for Kuwait in most cases needed to be moved upwards to retain sensitivity. In other words, an individual in the Kuwaiti population would need to score higher in a given diabetes risk score to achieve the same probability of having diabetes as an individual in the population from which the diabetes risk score was originally developed. This is a confirmation that different cut-off points are needed in different populations. However, the suggested cut-offs needed to be moved downwards for the Rotterdam and Danish scores. This may be due to the fact that both these risk scores lacked waist circumference and family history information, which are 2 risk factors that were independent predictors in our population. The absence of these 2 factors made those risk scores less capable of detecting undiagnosed diabetes in Kuwait.

One of the limitations of this study was that our blood glucose instrument was not the recognized gold standard for determining plasma glucose level. The National Committee for Clinical Laboratory Standards guidelines [24] states that the difference between the meter and the central laboratory in $95 \%$ of results should agree within 0.83 $\mathrm{mmol} / \mathrm{L}$ at glucose concentrations < $4.2 \mathrm{mmol} / \mathrm{L}$ and within $20 \%$ at glucose concentrations $\geq 4.2 \mathrm{mmol} / \mathrm{L}$. Our meter showed $95 \%$ of the measurements meeting the $<4.2 \mathrm{mmol} / \mathrm{L}$ requirement and $91 \%$ meeting the $\geq 4.2 \mathrm{mmol} / \mathrm{L}$ requirement [25]. It therefore came 


\begin{tabular}{|c|c|c|}
\hline $\begin{array}{l}\text { Risk score source/ } \\
\text { population }\end{array}$ & $\begin{array}{l}\text { Reference and } \\
\text { year }\end{array}$ & Variables \\
\hline $\begin{array}{l}\text { American Diabetes } \\
\text { Association }\end{array}$ & [19] 1995 & $\begin{array}{l}\text { Age, sex, BMI, female with history of delivery of a macrosomal child, } \\
\text { family history of diabetes in parent or sibling. }\end{array}$ \\
\hline Rotterdam, concise model & [16] 1999 & Age, sex, use of antihypertensives, presence of obesity. \\
\hline Cambridge & [18] 2000 & $\begin{array}{l}\text { Age, sex, use of prescribed antihypertensives or steroids, } \\
\text { diabetes family history, smoking status. }\end{array}$ \\
\hline Finnish & [20] 2003 & $\begin{array}{l}\text { Age, BMI, waist circumference, use of antihypertensives, history } \\
\text { of high blood glucose level, physical activity, consumption of } \\
\text { vegetables, fruits or berries. }\end{array}$ \\
\hline Danish & [17] 2004 & $\begin{array}{l}\text { Age, sex, BMI, known hypertension, physical activity at leisure time, } \\
\text { history of diabetes in parent. }\end{array}$ \\
\hline Indian & [21] 2005 & Age, waist circumference, physical activity, family history of diabetes. \\
\hline Thai & [14] 2006 & $\begin{array}{l}\text { Age, sex, BMI, waist circumference, hypertension, history of diabetes } \\
\text { in parent or sibling. }\end{array}$ \\
\hline Omani & [15] 2007 & $\begin{array}{l}\text { Age, waist circumference, BMI, family history of diabetes, current } \\
\text { hypertension status. }\end{array}$ \\
\hline Kuwaiti & Present study & $\begin{array}{l}\text { Age, waist circumference, use of blood pressure medication, family } \\
\text { history of diabetes in a sibling. }\end{array}$ \\
\hline
\end{tabular}

$B M I=$ body mass index

very close to the gold standard and was deemed adequate for the purpose of this survey. In our study, plasma glucose levels for the diagnosis of undetected diabetes were interpreted based on self-reported fasting of $>8$ hours. Those who did not report fasting were considered to have a random plasma glucose measurement with a cut-off at $11.1 \mathrm{mmol} / \mathrm{L}$ for diabetes, without confirming this on a separate day. This may have led to a slight underestimate of the burden of undetected diabetes in this community. Validation of the risk score in the same population and the use of a larger sample size would have further enhanced the generalizability of our results.

\section{Conclusions}

We found the crude prevalence of total diabetes to be $21.4 \%$, and almost one-fifth of the cases were previously undiagnosed. We provide a simple screening tool that identifies individuals who are at high risk of having diabetes in the Kuwaiti population. It relies

\begin{tabular}{|c|c|c|c|c|c|c|c|c|}
\hline \multirow[t]{3}{*}{$\begin{array}{l}\text { Risk score source/ } \\
\text { population }\end{array}$} & \multirow{3}{*}{$\begin{array}{l}\text { Original } \\
\text { cut-off } \\
\text { score }\end{array}$} & \multicolumn{2}{|c|}{$\begin{array}{l}\text { OC previously } \\
\text { published }\end{array}$} & \multicolumn{2}{|c|}{$\begin{array}{l}\text { OC when original cut- } \\
\text { off applied in this study }\end{array}$} & \multirow{3}{*}{$\begin{array}{c}\text { Adjusted } \\
\text { cut-off } \\
\text { score }\end{array}$} & \multicolumn{2}{|c|}{$\begin{array}{l}\text { OC when adjusted cut- } \\
\text { off applied in this study }\end{array}$} \\
\hline & & Sensitivity & Specificity & Sensitivity & Specificity & & Sensitivity & Specificity \\
\hline & & $\%$ & $\%$ & $\%$ & $\%$ & & $\%$ & $\%$ \\
\hline Thai & $\geq 6$ & 77 & 60 & 100 & 18 & $\geq 11$ & 83 & 54 \\
\hline Omani & $>10$ & 79 & 73 & 96 & 42 & $\geq 13$ & 70 & 64 \\
\hline $\begin{array}{l}\text { American Diabetes } \\
\text { Association }\end{array}$ & $\geq 10$ & 78 & 65 & 91 & 41 & $\geq 12$ & 78 & 56 \\
\hline Cambridge (pt A) & $\geq 0.080$ & 91 & 52 & 91 & 46 & - & - & - \\
\hline Cambridge (pt E) & $>0.199$ & 77 & 72 & 87 & 72 & $\geq 0.273$ & 78 & 78 \\
\hline Indian & $\geq 60$ & 73 & 60 & 87 & 50 & $\geq 70$ & 74 & 65 \\
\hline Finnish & $\geq 9$ & 77 & 66 & 83 & 65 & $\geq 9$ & 83 & 70 \\
\hline Rotterdam & $>6$ & 78 & 55 & 43 & 79 & $\geq 5$ & 78 & 41 \\
\hline Danish & $\geq 31$ & 73 & 74 & 39 & 87 & $\geq 21$ & 78 & 62 \\
\hline $\begin{array}{l}\text { Kuwaiti (present } \\
\text { study) }\end{array}$ & $\geq 32$ & 87 & 64 & - & - & - & - & - \\
\hline
\end{tabular}

OC = operating characteristics. 
mainly on known risk factors that are easy to measure and non-invasive. It is made up of only 4 questions (age, waist circumference, use of blood pressure medication and family history of diabetes in a sibling) but nevertheless it had $87 \%$ sensitivity and 64\% specificity. Most of the previously published risk scoreswere notapplicable to our Kuwaiti population; however their performance improved if the suggested cut-off values were adjusted appropriately.

\section{Acknowledgements}

The authors appreciate the effort of the following organizations for their support and funding: Roche Diagnostics and the Kuwait Diabetic Society.

\section{References}

1. Geiss LS et al. Changes in incidence of diabetes in U.S. adults, 1997-2003. American Journal of Preventive Medicine, 2006 30:371-377.

2. Lamendola C. Early and more vigorous detection of diabetes. Journal of Cardiovascular Nursing, 2003, 18:103-107.

3. King H, Rewers M. Global estimates for prevalence of diabetes mellitus and impaired glucose tolerance in adults. WHO Ad Hoc Diabetes Reporting Group. Diabetes Care, 1993, 16:157-177.

4. Harris MI, Eastman RC. Early detection of undiagnosed diabetes mellitus: a US perspective. Diabetes/Metabolism Research and Reviews, 2000, 16:230-236.

5. Dallo FJ, Weller SC. Effectiveness of diabetes mellitus screening recommendations. Proceedings of the National Academy of Sciences of the United States of America, 2003, 100:10574-10579.

6. Spijkerman AM et al. Prevalence of macrovascular disease amongst type 2 diabetic patients detected by targeted screening and patients newly diagnosed in general practice: the Hoorn screening study. Journal of Internal Medicine, 2004 256:429-436.

7. Spijkerman AM et al. Microvascular complications at time of diagnosis of type 2 diabetes are similar among diabetic patients detected by targeted screening and patients newly diagnosed in general practice: the Hoorn screening study. Diabetes Care, 2003, 26:2604-2608.

8. Haffner S. Diabetes and the metabolic syndrome--when is it best to intervene to prevent? Atherosclerosis. Supplements, 2006, 7:3-10.

9. Abdella $\mathrm{N}$ et al. Known type 2 diabetes mellitus among the Kuwaiti population. A prevalence study. Acta Diabetologica, 1996, 33:145-149.

10. Al-Nozha MM et al. Diabetes mellitus in Saudi Arabia. Saudi Medical Journal, 2004, 25:1603-1610.

11. El Mugamer IT et al. Diabetes, obesity and hypertension in urban and rural people of Bedouin origin in the United Arab Emirates. Journal of Tropical Medicine and Hygiene, 1995, 98:407-415.

12. Abdella $\mathrm{N}$ et al. Non-insulin-dependent diabetes in Kuwait: prevalence rates and associated risk factors. Diabetes Research and Clinical Practice, 1998, 42:187-196.
13. Report of the Expert Committee on the Diagnosis and Classification of Diabetes Mellitus. Diabetes Care, 2003, 26(Suppl. 1):S5-20.

14. Aekplakorn $W$ et al. A risk score for predicting incident diabetes in the Thai population. Diabetes Care, 2006, 29:1872-1877.

15. Al-Lawati JA, Tuomilehto J. Diabetes risk score in Oman: a tool to identify prevalent type 2 diabetes among Arabs of the Middle East. Diabetes Research and Clinical Practice, 2007, 77(3):438-444.

16. Baan CA et al. Performance of a predictive model to identify undiagnosed diabetes in a health care setting. Diabetes Care, 1999, 22:213-219.

17. Glümer C, Jørgensen T, Borch-Johnsen K. Targeted screening for undiagnosed diabetes reduces the number of diagnostic tests. Inter99(8). Diabetic Medicine, 2004, 21:874-880.

18. Griffin SJ et al. Diabetes risk score: towards earlier detection of type 2 diabetes in general practice. Diabetes/Metabolism Research and Reviews, 2000, 16:164-171.

19. Herman WH et al. A new and simple questionnaire to identify people at increased risk for undiagnosed diabetes. Diabetes Care, 1995, 18:382-387.

20. Lindström J, Tuomilehto J. The diabetes risk score: a practical tool to predict type 2 diabetes risk. Diabetes Care, 2003, 26:725-731.

21. Mohan V et al. A simplified Indian Diabetes Risk Score for screening for undiagnosed diabetic subjects. Journal of the Association of Physicians of India, 2005, 53:759-763.

22. Al-Lawati JA et al. Increasing prevalence of diabetes mellitus in Oman. Diabetic Medicine, 2002, 19:954-957.

23. Cowie CC et al. Prevalence of diabetes and impaired fasting glucose in adults in the U.S. population: National Health and Nutrition Examination Survey 1999-2002. Diabetes Care, 2006, 29:1263-1268.

24. NCCLS document C30-A2: point-of-care blood-glucose testing in acute and chronic care facilities, approved guidelines, 2 nd ed. Wayne, Pennsylvania, National Committee for Clinical Laboratory Standards, 2002

25. Hawkins RC. Evaluation of Roche Accu-Chek Go and Medisense Optium blood glucose meters. Clinica Chimica Acta, 2005, 353:127-131. 